\title{
Prescribing antibiotics in primary care
}

\section{Studies of antibiotic resistance emphasise the importance of conserving this non-renewable resource}

\section{RESEARCH, $\mathrm{p} 429$}

\section{Chris Del Mar dean}

Health Sciences and Medicine, Bond

University, Gold Coast,

QLD 4229, Australia

cdelmar@bond.edu.au

Competing interests: None declared.

Provenance and peer review: Commissioned; not externally peer reviewed.

\section{BMJ 2007;335:407-8}

doi:10.1136/bmj.39307.642963.80
In this week's $B M J$, Chung and colleagues report that community prescribing of a $\beta$ lactam antibiotic for acute respiratory infection doubled the prevalence of antibiotic resistant bacteria in individual children. ${ }^{1}$ This antibiotic resistance was transferred as a gene encoding $\beta$ lactamase from other species of bacteria to Haemophilus. What do these results mean for the future of antibiotic prescribing in general practice?

Antibiotic resistance will probably eventually appear by natural selection for every new antibiotic developed by the drug industry, and the race to produce new drugs ahead of resistance is run ever closer. Antibiotics should be thought of like oil, a non-renewable resource to be carefully husbanded. What we use now cannot be used some time in the future.

The problem is that there is no scientific solution to convincing people not to seize for their own benefit a common resource best nurtured for the good of the community. ${ }^{2}$ It is especially difficult for doctors treating a sick child not to provide (or, at least seem to provide) the best care, covering all possible outcomes, whatever the potential consequences for antibiotic resistance. What tools could clinicians have to balance the needs of the patient against protecting community resources?

It seemed for a while that draconian rationing would be needed to curb doctors' freedom to prescribe antibiotics-special administrative barriers to obstruct their use, rules of indications settled centrally, and so on. ${ }^{3}$ There are three reasons why this has not been necessary.

Firstly, one of the consequences of evidence based practice is the finding that antibiotics are minimally effective against most common childhood infections, mainly acute respiratory infections. This applies not only to infections commonly caused by viruses (colds ${ }^{4}$ and coughs ${ }^{5}$ ), but even those usually caused by bacteria (especially sore throats, ${ }^{6}$ and acute otitis media ${ }^{7}$ ). This message has been slow to infiltrate the community, although it is now appreciated by more people, and doctors now prescribe antibiotics less frequently, especially for sore throats and colds, if not for acute otitis media and bronchitis. ${ }^{8}$

Secondly, in some countries doctors delay the access to antibiotics as a type of educational ploy. A prescription is written to show willing, but either left to be picked up later, or given to the parents to be filled at the pharmacy only if the child does not recover. This is effective at reducing antibiotic use. ${ }^{8}$ However, there is a problem. It is slightly dishonest, implying that starting antibiotics later is no less effective than using them immediately,

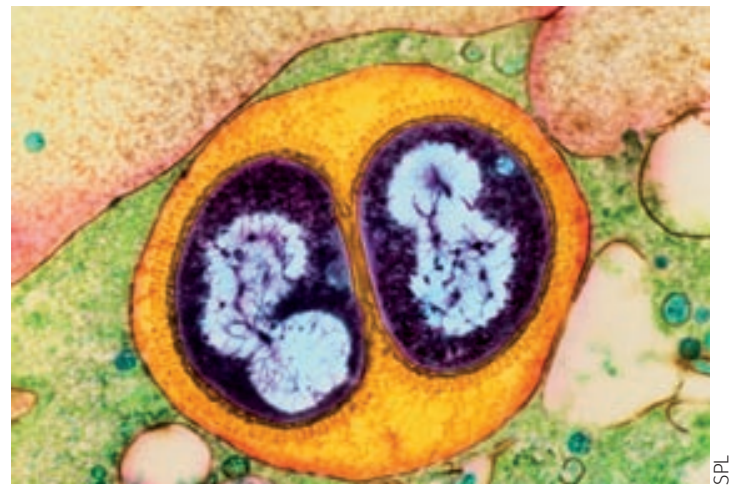

which in at least some cases is not true. ${ }^{9}$ In a perfect world we would educate patients in a less indirect if more difficult and longer way.

The third reason comes from the personalisation of resistance from a population perspective (remote and indirect) to the individual (immediate and direct). The theoretical possibility that uncontrolled antibiotic use would increase resistance was confirmed by empirical studies. Australian children prescribed antibiotics in the previous two months were twice as likely to have $\beta$ lactam penicillin resistant respiratory streptococci than children who were not prescribed these drugs, an effect that had not worn off six months later. ${ }^{10}$ The study by Chung and colleagues helps us better understand the mechanisms-how resistance is transferred between species in the child. ${ }^{1}$

Why does this matter? These data will be seized on by those trying to curb antibiotic prescribing to provide a more cogent argument for not using antibiotics. The argument now focuses on the risks of antibiotic resistance to the individual patient-carrying bacteria with those genes might confer a greater risk of resistance if they later have a severe infection that needs antibiotic rescue. This possibility opens an agenda for future research. Can we test whether people with a serious infection died because of a prescription of antibiotics for a more trivial infection in the recent past?

Another potential research question might come from trying different approaches entirely, thinking about that vast horde of bacteria we carry around with us. To what extent is infection the consequence of an imbalance of this population, rather than our current oversimplified model of a pathogenic bacterium entering the body? We can offset diarrhoea caused by antibiotics by populating the gastrointestinal tract with "friendly" commensal lactobacilli. ${ }^{11}$ Some preliminary research has shown the 
same can work for acute otitis media. ${ }^{12}$

In the meantime, doctors have new information to help convince patients and themselves that prescribing antibiotics for minor upper respiratory infections should be reserved for occasions when we really need them.

1 Chung A, Perera R, Brueggemann AB, Elamin AE, Harnden A, MayonWhite $R$, et al. Effect of antibiotic prescribing on antibiotic resistance in individual children in primary care: prospective cohort study. BMJ 2007 doi: 10.1136/bmj.39274.647465.BE.

2 Hardin G. The tragedy of the commons. Science 1968:162:1243-8.

3 Hawkey PM. Action against antibiotic resistance: no time to lose [editorial]. Lancet 1998;351:1298-9.

4 Arroll B, Kenealy T. Antibiotics for the common cold and acute purulent rhinitis. Cochrane Database Syst Rev 2005;(3):CD000247.

5 Smucny J, Fahey T, Becker L, Glazier R. Antibiotics for acute bronchitis. Cochrane Database Syst Rev 2004;(4):CD000245.

6 Del Mar CB, Glasziou PP, Spinks AB. Antibiotics for sore throat. Cochrane Database Syst Rev 2006;(4):CD000023.
7 Glasziou PP, Del Mar CB, Sanders SL, Hayem M. Antibiotics for acute otitis media in children. Cochrane Database Syst Rev 2004;(1): CD000219.

8 McCaig LF, Besser RE, Hughes JM. Trends in antimicrobial prescribing rates for children and adolescents. JAMA 2002;287:3096-102.

9 Spurling GK, Del Mar CB, Dooley L, Foxlee R. Delayed antibiotics for symptoms and complications of respiratory infections. Cochrane Database SystRev 2004;(4)2004:CD004417.

10 Nasrin D, Collignon PJ, Roberts L, Wilson EJ, Pilotto LS, Douglas RM. Effect of beta lactam antibiotic use in children on pneumococcal resistance to penicillin: prospective cohort study. BMJ 2002;324:28. 30.

11 Hickson M, D'Souza AL, Muthu N, Rogers TR, Want S, Rajkumar C, et al. Use of probiotic lactobacillus preparation to prevent diarrhoea associated with antibiotics: randomised double blind placebo controlled trial. BMJ 2007;335:80-3.

12 Roos K, Håkansson EG, Holm S. Effect of recolonisation with "interfering" alpha streptococci on recurrences of acute and secretory otitis media in children: randomised placebo controlled trial. BMJ 2001;322:1-4

\section{Reassessing normal blood pressure \\ Blood pressure should be evaluated and treated in the context of overall cardiovascular risk}

\section{RESEARCH, $\mathrm{p} 432$}

Ira S Nash associate professor Mount Sinai School of Medicine, Department of Medicine, Box 1118 , New York, NY 10029, USA ira.nash@mssm.edu

Competing interests: $\mathrm{SN}$ has received payment for speaking on behalf of Merck regarding its cholesterol lowering drugs but not for several years. ISN has no current ties to Merck.

Provenance and peer review: Commissioned; not externally peer reviewed.

BMJ 2007;335:408-9 doi: 10.1136/bmj.39310.540683.80
Atherothrombotic cardiovascular disease is now the leading cause of morbidity and mortality worldwide, with mortality exceeding that for the traditional scourges of infectious diseases, trauma, and malnutrition. ${ }^{1}$ Evidence suggests that most of the burden of disease is caused by unfavourable levels of several easily identified risk factors: arterial blood pressure, blood lipids, glucose concentrations, body mass index, tobacco use, and physical activity. ${ }^{2}$

Outcomes can be improved by selective interventions that drive risk factors towards optimum levels, but important questions remain about which risk factors should be treated, in which patients, to what levels, and by what means. The study in this week's $B M J$ by Conen and colleagues ${ }^{3}$ helps to answer some of these questions. It compares cardiovascular risk over two years in women with high normal blood pressure (130$139 / 85-89 \mathrm{~mm} \mathrm{Hg}$ ) to those with normal blood pressure (120-129/75-84 $\mathrm{mm} \mathrm{Hg}$ ) and those with baseline hypertension. It found that women with normal blood pressure had a lower risk of a major cardiovascular event (hazard ratio $0.61,95 \%$ confidence interval 0.48 to 0.76 ) and of incident hypertension $(0.42,0.40$ to 0.44$)$ than women with high normal blood pressure.

While some risk factors, such as tobacco use, are categorical, others-blood pressure and blood lipids in particular-are continuous over a wide range. The association of increased cardiovascular disease with the highest levels of these continuous risk factors led to a strategy of identifying thresholds for individual risk factors above which treatment was recommended. It is clear now, however, that such a strategy is flawed for two reasons.

Firstly, the notion that risk factors have a threshold value below which they do not confer risk, and above which they do, is biologically implausible and empirically false. The relation between blood pressure or serum cholesterol and ischaemic heart disease is "log linear," implying that a given change in the risk factor (such as a drop in systolic blood pressure of $10 \mathrm{~mm} \mathrm{Hg}$ or a reduction in low density lipoprotein cholesterol of $1 \mathrm{mmol} / \mathrm{l}$ ) reduces the incidence of heart disease by an equal proportion. This occurs regardless of its baseline value across a very broad range, and down to values rarely encountered in Western populations. ${ }^{4}$ Thus, relative risk reduction is constant, but absolute risk reduction is greater in patients with a higher baseline risk, regardless of why their baseline risk is high.

Observational data pooled from 61 prospective studies of over a million adults found proportional reductions in the incidence of mortality from stroke, ischaemic heart disease, and other vascular causes for a given reduction in systolic or diastolic blood pressure within each decade of life between 50 and 90 years. ${ }^{5}$ Risk of adverse outcomes declined down to a systolic blood pressure of $115 \mathrm{~mm} \mathrm{Hg}$, and a diastolic blood pressure of $75 \mathrm{~mm} \mathrm{Hg}$, beyond which insufficient data were available. No significant difference was seen in the relation between blood pressure and all cause mortality in men and women. The incremental risk associated with mildly raised blood pressure has been confirmed. ${ }^{6}$

The second reason why focusing on treatment thresholds of individual risk factors is a flawed strategy is that patients' overall risk of atherothrombotic disease depends on the interplay between all their risk factors. Applying a threshold for treatment for one particular risk factor ignores this and leads to recommendations to overtreat some low risk people and undertreat some high risk ones. For example, a young person who does not smoke and does not have diabetes, and who has a total cholesterol of $5.0 \mathrm{mmol} / \mathrm{l}$ and high density lipoprotein cholesterol of $1.4 \mathrm{mmol} / \mathrm{l}$, would have a relatively low absolute risk of cardiovascular disease, even if his or her systolic blood pressure were $160 \mathrm{~mm} \mathrm{Hg}{ }^{7}$ None the less, current guidelines would identify such a patient 
as needing antihypertensive treatment. ${ }^{89}$ Conversely, the same guidelines would not recommend antihypertensive treatment for an older person who smoked and who had a systolic blood pressure of $135 \mathrm{~mm} \mathrm{Hg}$, lower high density lipoprotein cholesterol, and higher total cholesterol, even though a reduction of systolic blood pressure of $10 \mathrm{~mm} \mathrm{Hg}$ would reduce absolute risk more in the second patient than the first because of the higher baseline risk. $^{7}$

The study by Conen and colleagues should be interpreted in this context. Because of its large number of participants and careful methodology, the findings of increased risk associated with high normal blood pressure in women are probably valid. This finding is consistent with the graduated risk of blood pressure over a broad range and has been seen in other studies. That said, it would be an oversimplification to say that the study defines a new threshold for "hypertension" that should force guidelines to be revised. Rather, it should remind practitioners that their goal should not be to treat blood pressure to achieve an arbitrary value, but to treat patients with a combination of interventions with known efficacy to lower their risk of atherothrombotic disease. This approach has been advocated for years, ${ }^{71011}$ but it is not widely embraced. Such an approach requires blood pressure (even at values below
130/90 $\mathrm{mm} \mathrm{Hg}$ ) to be interpreted as just one factor that contributes to overall risk.

1 WHO. Factsheet 310. 2007. www.who.int/mediacentre/factsheets/ fs310.pdf.

2 Canto JG, Iskandrian AE. Major risk factors for cardiovascular disease: debunking the "only 50\%" myth. JAMA 2003;290:947-9.

3 Conen D, Ridker PM, Buring JE, Glynn RJ. Risk of cardiovascular events among women with high normal blood pressure or blood pressure progression: prospective cohort study. BMJ 2007 doi: 10.1136/ bmi.39269.672188.AE.

4 Law MR, Wald NJ. Risk factor thresholds: their existence under scrutiny. BMJ 2002;324:1570-6.

5 Prospective Studies Collaboration. Age-specific relevance of usual blood pressure to vascular mortality: a meta-analysis of individual data for one million adults in 61 prospective studies. Lancet 2002;360:1903-13.

6 Kshirsagar AV, Carpenter M, Bang H, Wyatt SB, Colindres RE. Blood pressure usually considered normal is associated with an elevated risk of cardiovascular disease. Am J Med 2006;119:133-41.

7 Volpe M, Alderman MH, Furberg CD, Jackson R, Kostis JB, Laragh JH, et al. Beyond hypertension. Toward guidelines for cardiovascular risk reduction. Am J Hypertens 2004;17:1068-74.

8 Chobanian AV, Bakris GL, Black H, Cushman WC, Green LA, Izzo JL, et al. The seventh report of the joint national committee on prevention, detection, evaluation, and treatment of high blood pressure. The JNC 7 report. JAMA 2003;289:2560-72.

9 Guidelines Committee. European Society of Hypertension-European Society of Cardiology guidelines for the management of arterial hypertension. J Hypertens 2003;21:1011-53.

10 Alderman $\mathrm{MH}$. Blood pressure management: individualized treatment based on absolute risk and the potential for benefit. Ann Intern Med 1993;119:329-35.

11 Jackson R, Lawes CMM, Bennett DA, Milne RJ, Rodgers A. Treatment to lower blood pressure and blood cholesterol based on absolute cardiovascular risk. Lancet 2005;365:434-41.

\section{Recognising serious illness in feverish young children in primary care}

\section{Increasing the opportunity for prompt clinical assessment is the priority}

\begin{abstract}
Anthony Harnden university lecturer in general practice Department of Primary Health Care, University of Oxford, Oxford OX37LF

anthony.harnden@dphpc. ox.ac.uk

Competing interests: None declared.

Provenance and peer review: Commissioned; not externally peer reviewed.
\end{abstract}

BMJ 2007;335:409-10 doi: 10.1136/bmj.39295.383843.AD
The diagnosis and management of children with fever is an important part of primary care. Parents and children put their trust in general practitioners, who rightly worry about making a correct judgment. Although general practitioners have substantial clinical experience of assessing febrile children, half of children with meningococcal disease are sent home at first primary care consultation. ${ }^{1}$ How can this be and what can we do to improve our assessment of febrile children?

Several diagnostic difficulties face us. Firstly, serious bacterial infection in children is now rare. The successful introduction of Haemophilus influenzae type B and meningococcal $\mathrm{C}$ vaccines into the UK childhood immunisation schedule has led to a dramatic reduction in the prevalence of invasive infections caused by these organisms. ${ }^{23}$ Early reports suggest that the recently introduced conjugate pneumococcal vaccine will do the same. ${ }^{4}$ Studies have reported a large variation in estimated incidences of invasive bacterial disease in preschool children, but the quoted $1 \%{ }^{5}$ is almost certainly now a considerable overestimate. In England the only serious febrile illness in childhood whose incidence is increasing is Kawasaki disease, and that may be the result of improved recognition. ${ }^{6}$

The time point in the illness that the child is seen is crucial. Early symptoms of meningococcal diseasecoryza, sore throat, nausea-mimic those of common and self limiting viral infections. ${ }^{1}$ Reference to the precise time that the illness started may be helpful, but it is the velocity that is of key importance. ${ }^{7}$ The problem is that the velocity may not be linear or even exponential but may have sudden unexpected changes in acceleration resulting in marked and unexpected clinical deterioration. Indeed the established clinical paradigm of a dichotomous split between "viral" and "bacterial" infections is too simplistic-the velocity and clinical course reflects a complex interaction between viral infection, bacterial pathogens, and host response.

Evidence is lacking about the utility of vital signs in primary care. No established reference values exist. For example, we know that fever increases heart rate and that the rate varies according to the age of the child, whether the child is crying, and when antipyretic medication was last given. Children of the same age have different baseline heart rates and these rates may respond differently to fever irrespective of the severity of illness. Moreover, precise measurement of heart rate is difficult, especially in very young children with higher rates. Measurement error is a problem even when machinery is used.

Changes in NHS policy have led to the primary care of febrile children presenting outside office hours being delivered by an increasing number of professional groups. Doctors, nurses, staff working for the telephone 
helpline NHS Direct, out of hours centres, and accident and emergency departments may all have different levels of skill and experience. This is a major concern because the most solid evidence for recognising clinical severity in febrile children in primary care is a global assessment by an experienced clinician. ${ }^{89}$ The global assessment involves eliciting a clear history and careful observation of signs, including alertness, activity, colour, and respiratory effort.

Concerns from paediatricians about the late diagnosis of children with serious infection and the fragmentation of primary care led to the recent publication by the National Institute for Health and Clinical Excellence (NICE) of guidelines for the assessment and initial management of young children with feverish illness. ${ }^{10}$ The authors' objectives are laudable and the literature review is comprehensive, but their recommendations rely too much on consensus techniques and widespread consultation rather than being a rigorous interpretation of the evidence.

Although it may be practical in triage settings, it is premature to recommend that every febrile child visiting a general practitioner should routinely have a measurement of temperature, heart rate, respiratory rate, and capillary refill. A careful global assessment, examination, and medical record are rightly considered good practice. But over-reliance on vital signs with a low positive predictive value may result in the inappropriate referral of large numbers of children while children who develop a serious illness are sent away. General practitioners must not be persuaded to disregard their intuition. Nor does the "traffic light" system proposed by NICE add much value: children with "green" features are self evidently currently well; children with "red" features are very sick; and those with the "amber" features described-wakes only with prolonged stimulation and has nasal flaring and swelling of a limb or joint-would cause general practitioners to actively intervene in most circumstances.

To improve the care of children with feverish illness in primary care we should be offering less telephone advice and more opportunities for a prompt clinical assessment. We should recognise that we are seeing only a brief snapshot of a dynamic illness and should always empower and make it easy for the parent to consult again-even a few hours later-if symptoms deteriorate. We should trust our clinical intuition and refer and rerefer if concerned. Meanwhile a pressing need exists for more primary care research into the time course of febrile illnesses and the utility of a combination and sequential record of vital sign measurements before concrete recommendations can be made.

1 Thompson M, Ninis N, Perera R, Mayon-White R, Phillips C, Bailey L, et al. Clinical recognition of meningococcal disease in children and adolescents. Lancet 2006;367:397-403.

2 Slack MP, Azzopardi HJ, Hargreaves RM, Ramsay ME. Enhanced surveillance of invasive Haemophilus influenzae disease in England, 1990 to 1996: impact of conjugate vaccines. Pediatr Infect Dis J 1998;17:S204-7.

3 Trotter CL, Andrews NJ, Kaczmarski EB, Miller E, Ramsay ME. Effectiveness of meningococcal serogroup $C$ conjugate vaccine 4 years after introduction. Lancet 2004;364:365-7.

4 Whitney CG, Farley MM, Hadler J, Harrison LH, Bennett NM, Lynfield $R$, et al. Decline in invasive pneumococcal disease after the introduction of protein-polysaccharide conjugate vaccine. $N$ EnglJ Med 2003;248:1737-46.

5 Van den Bruel A, Bartholomeeusen S, Aertgeerts B, Truyers C, Buntinx $F$. Serious infections in children: an incidence study in family practice. BMC Fam Pract 2006;7:23.

6 Harnden A, Alves B, Sheikh A. Rising incidence of Kawasaki disease in England. BMJ 2002;324;1424-5.

7 Kilpi T, Anttila M, Kallio MJ, Peltola H. Severity of childhood bacterial meningitis and duration of illness before diagnosis. Lancet 1991:338:406-9.

8 McCarthy PL, Jekel JF, Stashwick CA, Spiesel SZ, DolanTF, Sharpe $M R$, et al. Further definition of history and observation variables in assessing febrile children. Pediatrics 1981;67:687-93.

9 Van den Bruel A, Aertgeerts B, Bruyninckx R, Aerts M, Buntinx F. Signs and symptoms for diagnosis of serious infections in children: a prospective study in primary care. BrJ Gen Pract 2007; 57:538-46.

10 National Institute for Health and Clinical Excellence. Feverish illness in children-assessment and initial management in children younger than 5 years. 2007 . (NICE clinical guideline No 47.) http://guidance. nice.org.uk/CG47

\section{Pain and heavy bleeding with intrauterine contraceptive devices}

\section{These devices are safe but underused in developed countries}

Sally B Rose research fellow Women's Health Research Centre, Department of Primary Health Care and General Practice, University of Otago, Wellington. School of Medicine and Health Sciences, PO Box 7343, Wellington, New Zealand sally.rose@otago.ac.nz

Competing interests: None declared.

Provenance and peer review: Commissioned; not externally peer reviewed.

BMJ 2007;335:410-11

doi: $10.1136 /$ bmj.39288.584086.80
The two types of intrauterine contraceptive device have very different menstrual side effects. The newer hormonal levonorgestrel intrauterine system (LNG-IUS or Mirena) reduces menstrual flow, whereas the copper bearing devices may induce longer, heavier, and more painful periods. Pain and heavy menstrual bleeding are common reasons for discontinuing use of an intrauterine device within the first year. Non-steroidal antiinflammatory drugs (NSAIDs) can reduce cramping and blood flow in women with and without devices.

A recent Cochrane review by Grimes and colleagues evaluated data from 15 randomised controlled trials investigating the effect of NSAIDs on treatment or prevention of pain and bleeding due to an intrauterine contraceptive device. ${ }^{1}$ Trials meeting selection criteria were conducted in 10 countries using a range of treatments
(NSAID compared with placebo, another NSAID, or another type of drug) and a variety of quantitative and qualitative outcome measures-factors that precluded a meta-analysis of the data. Although many of the trials had methodological weaknesses, data from treatment trials showed an overall beneficial effect of NSAIDs on pain and bleeding outcomes, but data from prevention trials were inconsistent. In otherwise asymptomatic women NSAIDs reduced pain or bleeding (or both) in three studies, did not differ from placebo in two studies, and reduced bleeding but not pain in another. A large rigorously conducted trial of 2019 first time users in Chile did not support the prophylactic use of ibuprofen compared with placebo to reduce rates of removal of devices because of pain or bleeding. ${ }^{2}$

Given the availability, low cost, and general safety 
of NSAIDs in women of reproductive age, this review supports a therapeutic practice many clinicians will be familiar with. A short course of NSAIDs during menses is appropriate to treat persistent or troublesome pain or bleeding with an intrauterine device, providing there are no contraindications. Grimes and colleagues concluded, however, that there are insufficient data to recommend the optimal type and dose of NSAID. Prescribers must weigh up the risk of adverse effects, convenience related to dosing frequency, cost, and local availability. ${ }^{1}$

For women in whom NSAIDs do not reduce bleeding to an acceptable level, tranexamic acid is effective but can have more unpleasant side effects. ${ }^{1}$ These conclusions are consistent with a recent evidence based guide on long term use of intrauterine devices which also recommended that, where pain or heaving bleeding persist for more than six months, women should be checked for gynaecological problems and clinical signs of anaemia. ${ }^{3}$ Unless prohibited by availability or cost, the levonorgestrel intrauterine system may be considered for women who cannot tolerate menstrual problems caused by a copper bearing device. This hormone bearing device has both contraceptive and (off-label) therapeutic uses, with evidence to support its role in treating women with anaemia, dysmenorrhoea, and menorrhagia. ${ }^{4}$

Intrauterine contraceptive devices are suitable for use by most women (including younger and nulliparous women),${ }^{5}$ are cost effective when continued long term (Mirena is approved for five years, copper devices for up to 10 years), and have health benefits beyond simple contraception. ${ }^{46}$ Fertility is restored on their removal, and unlike other forms of contraception their efficacy does not depend on the user's behaviour. Consequently, such devices are an excellent alternative to female sterilisation (which women may later regret), ${ }^{7}$ and are a long term alternative to other methods of birth control prone to misuse or failure. Despite being the most common form of reversible contraception used by women of reproductive age worldwide, these devices are underused in developed countries. ${ }^{8}$ Nearly half of all users are in China, while only $6 \%$ of women of reproductive age in the United Kingdom, 4.6\% in Australia and New Zealand, and fewer than $1 \%$ in the United States use this method of contraception. ${ }^{8}$
Reluctance to offer or use intrauterine devices seems to stem largely from the experience with the Dalkon Shield in the 1970s, which caused pelvic infections that had serious health consequences for many thousands of women. Legal action against manufacturers of that and other devices led to a sharp decline in the use of all intrauterine contraceptive devices and their subsequent withdrawal from the US market in the 1980s. ${ }^{9}$ Since then, misconceptions based on outdated information have persisted, such as the belief that these devices cause pelvic inflammatory disease and infertility. Evidence from randomised controlled trials and from case-control and cohort studies suggests there might be a small increased risk in the first 20 days after insertion, but beyond that the risk of upper genital tract infection does not differ from that in non-users. ${ }^{10}$ Pelvic inflammatory disease is frequently caused by untreated chlamydia, ${ }^{11}$ and it is good practice to test for and treat asymptomatic infection before inserting a device ${ }^{10}$ and to advise the use of condoms to protect against sexually transmitted infections.

1 Grimes DA, Hubacher D, Lopez LM, Schulz KF. Non-steroidal antiinflammatory drugs for heavy bleeding or pain associated with intrauterine-device use. Cochrane Database Syst Rev 2006;(4): CD006034.

2 Hubacher D. Preventing copper IUD removals due to side effects among first time users: placebo-controlled randomized controlled trial to study the effect of prophylactic ibuprofen. Hum Reprod 2007;21:1467-72.

3 Penney G, Brechin S, de Souza A, Bankowska U, Belfield T, Gormley $M$, et al. The copper intrauterine device as long-term contraception. FFPRHC guidance (January 2004). J Fam Plann Reprod Health Care 2004:30:29-41; quiz 42

4 Jensen JT. Contraceptive and therapeutic effects of the levonorgestrel intrauterine system: an overview. Obstet Gynecol Survey 2005;60:604-12.

5 World Health Organization. Family and Reproductive Health Programme. Medical eligibility criteria for contraceptive use. 3 rd ed. Geneva, Switzerland: WHO, 2004.

6 Hubacher D, Grimes DA. Noncontraceptive health benefits of intrauterine devices: a systematic review. Obstet Gynecol Survey 2002;57:120-8.

7 Hillis SD, Marchbanks PA, Tylor LR, Peterson HB. Poststerilization regret: findings from the United States collaborative review of sterilization. Obstet Gynecol 1999;93:889-95.

8 United Nations Department of Economic and Social Affairs Population Division. World contraceptive use 2005. New York: United Nations, 2005. www.un.org/esa/population/publications contraceptive2005/WCU2005.htm

9 Hubacher D. The checkered history and bright future of intrauterine contraception in the United States. Perspect Sexual Reprod Health 2002;42:98-103.

10 Grimes DA. Intrauterine device and upper-genital-tract infection. Lancet 2000:356:1013.

11 Scholes D, Stergachis A, Heidrich FE, Andrilla H, Holmes KK, Stamm WE. Prevention of pelvic inflammatory disease by screening for cervical chlamydial infection. N Engl J Med 1996;334:1362-6.

\section{Chronic fatigue syndrome or myalgic encephalomyelitis NICE guidelines pave the way forward for patients and doctors}

\section{PRACTICE, p 446}

BMJ 2007;335:411-12 doi:10.1136/bmj.39316.472361.80
The uncertainty inherent in making a diagnosis of chronic fatigue syndrome (CFS) is reflected by the variety of names (such as myalgic encephalomyelitis; $\mathrm{ME}$ ) it has been given. The names reflect the hope that such labels can impose some certainty where little exists. Many doctors are reluctant to make a diagnosis of CFS, with half not even believing it exists. ${ }^{1}$ The consequences of this uncertainty and reluctance have been that patients hear mixed messages and often receive poor, if any, care. ${ }^{2}$ It is therefore a welcome relief that the National Institute for Health and Clinical Excellence (NICE) has just published clinical guidelines on the diagnosis and management of this disease. ${ }^{3}$ In this week's BMJ, Baker and Shaw summarise the guidelines. ${ }^{4}$

How has the development of these guidelines 
Peter White professor of psychological medicine,Barts and the London NHS Trust and Queen Mary School of Medicine and Dentistry, St Bartholomew's Hospital, London EC1A 7BE

p.d.white@qmul.ac.uk

Maurice Murphy cons ultant physician

Jill Moss founding chair,

Association of Young People with ME, PO Box 5766, Milton Keynes, MK101AQ

George Armstrong co-chair Action for ME, Bristol BS16BY Sir Peter Spencer chief executive officer

Competing interests: PDW and MM work with a colleague who was a member of the guideline development group (GDG). PDW does consultancy work for the Department for Work and Pensions and Swiss Re, a re-insurance company. AYME's medical adviser was a member of the GDG.

Provenance and peer review: Commissioned; not peer reviewed. come about? Eleven years ago, three UK royal colleges agreed that $\mathrm{CFS} / \mathrm{ME}$ existed as an independent diagnosis and that treatments were possible. ${ }^{5}$ Unfortunately, this had little effect on the provision of services. In 2002, an independent report was endorsed by the chief medical officer for England, which recommended that services should be routinely provided. ${ }^{6}$ The government responded positively by providing three years of ring fenced central funds to set up and support specific CFS/ME services, albeit only in England and with insufficient funds to cover the country. Some 50 services were created or enhanced, but they faced two fundamental problems-how to make an accurate diagnosis of CFS/ME and how then to treat it?

NICE has now come up with some answers, ${ }^{34}$ based on a recent systematic review, ${ }^{7}$ as well as using formal consensus techniques where no evidence exists. The guideline development group included members of all relevant healthcare professions and three patient representatives. The draft guidelines were circulated to numerous stakeholders, who provided more than 2000 pages of comments that helped to shape the final guidelines.

What are the main messages for doctors? CFS/ $\mathrm{ME}$ exists and effective treatments are available. We remain unsure of its causes, pathophysiology, or how to classify it, but there are many other remediable conditions of which this is also true. It serves no purpose to disbelieve the patient, who may be severely disabled as a consequence of the illness and handicapped by the lack of medical support or understanding.

The diagnosis is a clinical one-no diagnostic tests are currently available, but prolonged malaise or fatigue after exertion are characteristic features. It is important to exclude alternative and common diagnoses, such as endocrine diseases, sleep apnoea, and mood disorders. Controversy has previously centred around management, and it is here that the NICE guidelines are particularly helpful. It may surprise doctors that the guidelines emphasise the need to negotiate management programmes with the patient and not to coerce them into specific treatments, but some patients have reported that this occurs. ${ }^{6}$

In primary care, early management of symptoms, advice on activities and occupation, and criteria for specialist referral are emphasised. In specialist care, cognitive behaviour therapy and graded exercise therapy should be available, because these treatments show "the clearest research evidence of benefit," 3 and the guidelines include the principles and practice of both treatments. Sufficient evidence was not available to recommend such treatments for severely disabled people and children. Instead, the consensus view recommended a watered down version of activity management based on the principles of these treatments. Patient groups prefer the term graded activity, which incorporates the diversity of such management programmes. Specific advice regarding children and young people included earlier diagnosis, referral criteria, and both advice and liaison over education.
Will the guidelines be useful and can they be implemented? The answers are yes and why not? The guidelines may seem too obvious to be useful, but this view underestimates the previous disagreement about how to help patients. A survey conducted by a national patient charity reported that half of patients found graded exercise therapy harmful, ${ }^{8}$ although a later survey showed that this was related to inappropriate advice or lack of therapeutic support. ${ }^{9}$ This guidance should remove arguments about whether to provide a service and what such a service should include. The implementation requires primary care trusts to ensure local provision of services in the large areas of the United Kingdom where no service exists. Existing services should ensure that their provision is consistent with the guidelines. General practitioners should be confident in making a diagnosis, providing initial management and referral.

Two large UK Medical Research Council funded trials of rehabilitation currently under way-one of which includes pacing developed in collaboration with a patient group-will provide better information about the most cost effective treatments. ${ }^{10} 11$ The history of this field has been littered with miscommunications and misunderstandings. NICE has forged a remarkable consensus and created a unique opportunity for us all to work together to provide the right care for the right patients at the right time.

1 Thomas MA, Smith AP. Primary healthcare provision and chronic fatigue syndrome: a survey of patients' and general practitioners' beliefs. BMC Fam Pract 2005;6:49.

2 Deale A, Wessely S. Patients' perceptions of medical care in chronic fatigue syndrome. Soc Sci Med 2001;52:1859-64.

3 National Institute for Health and Clinical Excellence. Clinical guideline CG53. Chronic fatigue syndrome/myalgic encephalomyelitis (or encephalopathy): diagnosis and management. London, NICE, 2007. http://guidance.nice.org.uk/CG53.

4 Baker R, Shaw EJ. Diagnosis and management of chronic fatigue syndrome or myalgic encephalomyelitis (or encephalopathy): summary of NICE guidance. BMJ 2007 doi: 10.1136/ bmj.39302.509005.AE

5 Royal Colleges. Chronic fatigue syndrome: report of a joint working group of the Royal Colleges of Physicians, Psychiatrists and General Practitioners. London: Royal College of Physicians, 1996. www. rcplondon.ac.uk/pubs/brochure. aspx? $\mathrm{e}=60$.

6 CFS/ME Working Group. A report of the CFS/ME working group: report to the chief medical officer of an independent working group. London: Department of Health, 2002. www. dh.gov.uk/en/Publicationsandstatistics/Publications/ PublicationsPolicyAndGuidance/DH_4064840.

7 Chambers D, Bagnall A-M, Hempel S, Forbes C. Interventions for the treatment, management and rehabilitation of patients with chronic fatigue syndrome/myalgic encephalomyelitis: an updated systematic review. J R Soc Med 2006;99:506-20.

8 Action for ME. Severely neglected: ME in the UK, membership survey. 2001. www.afme.org.uk/res/img/resources/ Severely\%20Neglected.pdf.

9 Action for ME. All about ME: an introduction. 2004. www.afme.org. uk/res/img/resources/All\%20about\%20ME.pdf.

10 Wearden AJ, Riste L, Dowrick C, Chew-Graham C, Bentall RP, Morriss RK, et al. Fatigue intervention by nurses evaluation-the FINE trial. A randomised controlled trial of nurse led self-help treatment for patients in primary care with chronic fatigue syndrome: study protocol. BMC Med 2006;4:9.

11 White PD, Sharpe MC, Chalder T, DeCesare JC, Walwyn R; on behalf of the PACE trial group. Protocol for the PACE trial: a randomised controlled trial of adaptive pacing, cognitive behaviour therapy, and graded exercise, as supplements to standardised specialist medical care versus standardised specialist medical care alone for patients with the chronic fatigue syndrome/myalgic encephalomyelitis or encephalopathy. BMC Neurol 2007;7:6. 